Check for updates

Cite this: Chem. Sci., 2019, 10, 3535

๑ All publication charges for this article have been paid for by the Royal Society of Chemistry

\section{Rapid room temperature synthesis of red iridium(III) complexes containing a four-membered Ir-S-C-S chelating ring for highly efficient OLEDs with EQE over $30 \% \dagger$}

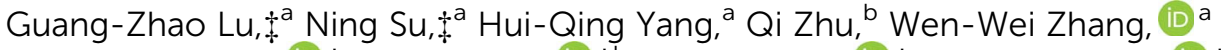 \\ You-Xuan Zheng, (D)*a Liang Zhou, (D)*b Jing-Lin Zuo, (D)*a Zhao-Xu Chen (D)*a \\ and Hong-Jie Zhang (D) ${ }^{b}$
}

Three red cyclometalated iridium(II) complexes (4tfmpq) $)_{2} \operatorname{Ir}(\operatorname{dipdtc}), \quad(4 \mathrm{tfmpq})_{2} \mid \mathrm{r}(\mathrm{dpdtc})$ and $(4 \mathrm{tfmpq})_{2} \mathrm{Ir}(\mathrm{Czdtc}) \quad$ (4tfmpq $=4$-(4-(trifluoromethyl)phenyl)quinazoline, dipdtc $=\mathrm{N}, \mathrm{N}$-diisopropyl dithiocarbamate, dpdtc $=\mathrm{N}, \mathrm{N}$-diphenyl dithiocarbamate, and Czdtc $=\mathrm{N}$-carbazolyl dithiocarbamate) containing the unique four-membered $\mathrm{I}-\mathrm{S}-\mathrm{C}-\mathrm{S}$ backbone ring were synthesized in five minutes at room temperature with good yields, and the Gibbs free energy calculation results indicate that all reactions are exothermic and thermodynamically favorable processes. The emission colors $\left(\lambda_{\text {peak }}=641-\right.$ $611 \mathrm{~nm})$, photoluminescence quantum efficiencies $\left(\Phi_{\mathrm{P}}=58.3-93.0 \%\right)$ and bipolar properties can be effectively regulated by introducing different electron-donating substituents into the dithiocarbamate ancillary ligands. Employing these emitters, organic light emitting diodes (OLEDs) with double emissive layers exhibit excellent performances with a maximum brightness over $60000 \mathrm{~cd} \mathrm{~m}^{-2}$, a maximum current efficiency of $40.68 \mathrm{~cd} \mathrm{~A}^{-1}$, a maximum external quantum efficiency ( $E Q E_{\max }$ ) of $30.54 \%$, and an EQE of $26.79 \%$ at the practical luminance of $1000 \mathrm{~cd} \mathrm{~m} \mathrm{~m}^{-2}$. These results demonstrate that Ir(III) complexes with sulfur-containing ligands can be rapidly synthesized at room temperature, which is key to the production of metal luminescent materials for large-scale application in highly efficient OLEDs.
Received 16th December 2018 Accepted 9th February 2019

DOI: $10.1039 / c 8 s c 05605 f$

rsc.li/chemical-science including relatively short triplet excited-state lifetime, high phosphorescence quantum yields and excellent color tunability. ${ }^{1}$ Especially, iridium(III) complexes are the most important emitters, and the demand for phosphorescent materials during OLED industrialization is particularly large. ${ }^{2}$ In order to speed up the process of OLED industrialization, cost reduction is extremely important. But for the production of most Ir(III) complexes, the last reaction process is always to reflux the $\left[\left(\mathrm{C}^{\wedge} \mathrm{N}\right)_{2} \operatorname{Ir}(\mu-\mathrm{Cl})\right]_{2}$ chloride-bridged dimer with cyclometalated or ancillary ligands at high temperature for a long time, which would inevitably increase the manpower and cost. ${ }^{3}$ It is important, but difficult to find suitable ligands which can form phosphorescent complexes at room temperature efficiently to reduce the cost of OLED industrialization significantly. ${ }^{4}$

For the previously reported Ir(III) complexes, ancillary ligands such as acetylacetone (acac) or 2-pyridinecarboxylic acid (pic) with the central iridium atom mainly formed six or fivemembered ring structures. But Ir(III) complexes containing four-membered ring structures make the angle formed by the two coordinated atoms of the ancillary ligand and the iridium atom reduced, suggesting that four-membered metallocycles would possess greater coordination strain energy. ${ }^{5}$ However, four-membered ring structures of $\operatorname{Ir}(\mathrm{III})$ complexes with sulfur

$\ddagger \mathrm{Lu}$ and Su have the same contributions to this paper. 
atoms in the ancillary ligands are rarely studied in OLEDs, ${ }^{6}$ and there is no new progress in the research of $\operatorname{Ir}(\mathrm{III})$ complexes containing the four-membered ring based on the Ir-S-C-S backbone. Moreover, these ancillary ligand derivatives have strong selectivity to the cyclometalated ligand for efficient Ir(III) complexes. Furthermore, in comparison with those welldeveloped green Ir(III) complexes, efficient red emitters are limited and the performances of red OLEDs are still not satisfactory owing to the energy gap law. ${ }^{7}$ For example, Suh et al. reported an $\operatorname{Ir}(\mathrm{mphmq})_{2}(\mathrm{tmd})$ based high-performance device with a maximum EQE of $24.3 \%$ and the CIE coordinates of $(0.65,0.35) .{ }^{7 f}$ Lately, Yang et al. reported devices using (ptq) $)_{2} \operatorname{Ir}(\mathrm{acac})$ with the CIE coordinates of $(0.61,0.36)$ and a maximum EQE of $22.9 \% .^{7 g}$ Cho et al. reported a thiophenephenylquinoline-based Ir(III) complex (Th-PQ) ${ }_{3}$ Ir and the corresponding OLEDs achieved a maximum EQE of $21.3 \%$ with an EL emission peak at $612 \mathrm{~nm}$ adopting solution-processed technology. ${ }^{\text {h }}$ Recently, Chi et al. reported a bis-tridentate $\operatorname{Ir}(\mathrm{III})$ complex of $[\operatorname{Ir}(\mathrm{mimb})$ (L3)] and the corresponding devices achieved the highest results of a maximum EQE of $27.4 \%$ with CIE coordinates of $(0.63,0.38) .{ }^{7 i}$

With this consideration, three sulfur atom containing dithiocarbamate derivatives constructed with different electrondonating groups (dipdtc $=N, N$-diisopropyl dithiocarbamate, dpdtc $=N, N$-diphenyl dithiocarbamate, and Czdtc $=N$-carbazolyl dithiocarbamate) as ancillary ligands were developed for Ir(III) complexes $(4 \mathrm{tfmpq})_{2} \operatorname{Ir}(\text { dipdtc), (4tfmpq) })_{2} \operatorname{Ir}($ dpdtc) and $(4 \mathrm{tfmpq})_{2} \operatorname{Ir}(\mathrm{Czdtc}) \quad$ using the electron-deficient 4-(4-(trifluoromethyl)phenyl)quinazoline (4tfmpq) moiety as the cyclometalated ligand (Scheme 1) in this paper. Diphenylamine and carbazole are very classical hole transport units in OLED hole transport and host materials. The application of diphenylamine

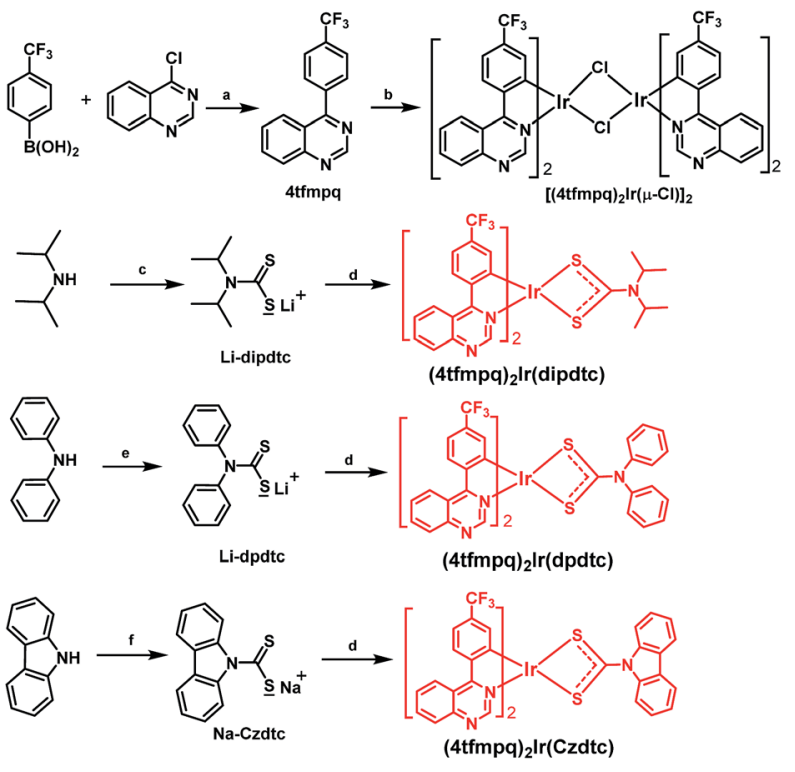

(a) $\mathrm{Pd}\left(\mathrm{PPh}_{3}\right)_{4}, \mathrm{Na}_{2} \mathrm{CO}_{3}, \mathrm{THF}-\mathrm{H}_{2} \mathrm{O}, 70^{\circ} \mathrm{C}, 12 \mathrm{~h}$; (d) $\mathrm{EtOCH}_{2} \mathrm{CH}_{2} \mathrm{OH}, \mathrm{rt}, 5 \mathrm{~min}$; (b) $\mathrm{IrCl}_{3}, \mathrm{EtOCH}_{2} \mathrm{CH}_{2} \mathrm{OH}, 115^{\circ} \mathrm{C}, 12 \mathrm{~h}$; (c) $\mathrm{LiOH}, \mathrm{CS}_{2}$, benzene- $\mathrm{H}_{2} \mathrm{O}$, rt, $2 \mathrm{~h}$; (e) $n-\mathrm{BuLi}, \mathrm{CS}_{2}, 0^{\circ} \mathrm{C} 12 \mathrm{~h}$; (f) $\mathrm{NaH}, \mathrm{CS}_{2}, 40^{\circ} \mathrm{C}, 3 \mathrm{~h}$; and carbazole in phosphorescent materials is more conducive to the balance of the distribution of holes and electrons, and is crucial for improving device efficiency and reducing roll-off. Moreover, the stable dithiolate compounds can reduce the work function of the emitter and the turn-on voltage in OLEDs. ${ }^{8}$ In addition, due to the nitrogen frame of the $4 \mathrm{tfmpq}$ ligand, these complexes would have bipolar properties, which are beneficial for their device performances. ${ }^{9}$

\section{Results and discussion}

\section{Preparation and characterization of complexes}

As shown in Scheme 1, three Ir(III) complexes were synthesized by the reaction of the $\left[\left(\mathrm{C}^{\wedge} \mathrm{N}\right)_{2} \operatorname{Ir}(\mu-\mathrm{Cl})\right]_{2}$ chloride-bridged dimer with dithiocarbamate derivatives. The four-membered heterocycle containing dithiocarbamate derivatives in $(4 \mathrm{tfmpq})_{2}$ $\operatorname{Ir}(\text { dipdtc), (4tfmpq })_{2} \operatorname{Ir}($ dpdtc $)$ and $(4 \mathrm{tfmpq})_{2} \operatorname{Ir}(\mathrm{Czdtc})$ were accessed by employing electron-rich units with bulkier backbone substituents to favor $S, S$-chelation of the electron-deficient Ir(III) center. ${ }^{5,6,10}$ Thus, the isopropyl, phenyl and carbazolyl moieties tend to push the lone pairs of electrons on the nitrogen atoms toward the metal center, which could greatly favor the chelating bonding mode. ${ }^{\mathbf{5 , 6 , 1 1}}$ All complexes can be synthesized at room temperature in $5 \mathrm{~min}$ with high yields above $70 \%$ and good thermal stability (with decomposition temperature above $370{ }^{\circ} \mathrm{C}$, Table 1 and Fig. S1†) owing to the strong coordination capability of the sulfur atom with the iridium atom, which is also helpful to boost their sublimation yields (>90\%). Because most Ir(III) complexes were prepared at high temperature for a long time, the sulfur atom containing ligands developed in this study can reduce the cost of materials and OLED industrialization significantly.

To further explore the reason for the rapid synthesis of these Ir(III) complexes, density functional theory (DFT) calculations at the B3LYP/Lanl2DZ ${ }^{12,13}$ level with the solvent effect treated using a SMD model ${ }^{\mathbf{1 4}}$ were conducted. The calculated Gibbs free energy changes, $\Delta G$, indicate that all three reactions are exothermic and thermodynamically favorable processes (from -59.4 to $-94.9 \mathrm{~kJ} \mathrm{~mol}^{-1}$, Fig. 1). Assuming the formation of the two Ir-S bonds is stepwise, the kinetics of the complex formation by flexibly scanning the Ir-S bond length for the reaction of $(4 \mathrm{tfmpq})_{2} \operatorname{Ir}($ dipdtc) were examined. The obtained potential energy surfaces show that as the S and Ir approach each other, the energy of the system gradually decreases until the equilibrium S-Ir bond length is reached. Further reduction of the S-Ir distance leads to a sharp energy increase (Fig. S2 $\dagger$ ). Hence, the formation of the S-Ir coordination bond does not involve the transition state of the conventional sense, and it is not necessary to overcome the corresponding energy barrier. The calculated free energy changes $\Delta G\left(-42.4 \mathrm{~kJ} \mathrm{~mol}^{-1}\right.$, Fig. S3 $\left.\dagger\right)$ further demonstrate that the formation of the first Ir-S bond is thermodynamically favorable. The formation of the second Ir-S bond is similar to the first one, both kinetically and thermodynamically (-60.6 $\mathrm{kJ} \mathrm{mol}^{-1}$, Fig. S3†).

Molecular structures by the ORTEP drawing of the $\operatorname{Ir}($ III) complexes (4tfmpq) $)_{2} \operatorname{Ir}(\text { dipdtc) and (4tfmpq) })_{2} \operatorname{Ir}$ (Czdtc) are shown in Fig. 2, and the crystallographic data and the selected 
Table 1 Photophysical data of (4tfmpq) 2 Ir(dipdtc), (4tfmpq) 2 Ir(dpdtc) and (4tfmpq) 2 Ir(Czdtc) in $\mathrm{CH}_{2} \mathrm{Cl}_{2}$ solution

\begin{tabular}{|c|c|c|c|c|c|c|c|}
\hline Complex & $T_{\mathrm{d}}^{a}\left({ }^{\circ} \mathrm{C}\right)$ & $\operatorname{Absorption}^{b}(\lambda \mathrm{nm})$ & $\operatorname{Emission}^{b}\left(\lambda_{\max } \mathrm{nm}\right)$ & $\tau_{298 \mathrm{~K}}^{b}(\mu \mathrm{s})$ & $\Phi_{\mathrm{P}}^{c}(\%)$ & $E_{\mathrm{T}}^{d}(\mathrm{eV})$ & 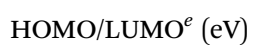 \\
\hline$(4 \mathrm{tfmpq})_{2} \operatorname{Ir}($ dipdtc $)$ & 384 & $263 / 285 / 453 / 592$ & 641 & 1.41 & 58.3 & 2.04 & $-5.44 /-3.19$ \\
\hline$(4 \mathrm{tfmpq})_{2} \operatorname{Ir}(\mathrm{dpdtc})$ & 376 & $261 / 324 / 443 / 543$ & 628 & 1.55 & 84.3 & 2.07 & $-5.50 /-3.20$ \\
\hline
\end{tabular}

${ }^{a}$ Decomposition temperature. ${ }^{b}$ Measured in degassed $\mathrm{CH}_{2} \mathrm{Cl}_{2} \cdot{ }^{c} \Phi$ : emission quantum yields were calculated with the fac-Ir(ppy) ${ }_{3}$ standard in degassed $\mathrm{CH}_{2} \mathrm{Cl}_{2}$ solution $\left(\Phi_{\mathrm{P}}=0.4\right) .{ }^{d} E_{\mathrm{T}}$ (triplet energy): estimated from the highest-energy peaks of the $77 \mathrm{~K}$ phosphorescence spectra in $\mathrm{CH}_{2} \mathrm{Cl}_{2}\left(10^{-5} \mathrm{M}\right) .{ }^{e} \mathrm{HOMO}(\mathrm{eV})=-\left(E_{\mathrm{ox}}-E_{1 / 2, \mathrm{Fc}}\right)-4.8, \mathrm{LUMO}(\mathrm{eV})=\mathrm{HOMO}+E_{\text {bandgap }}$
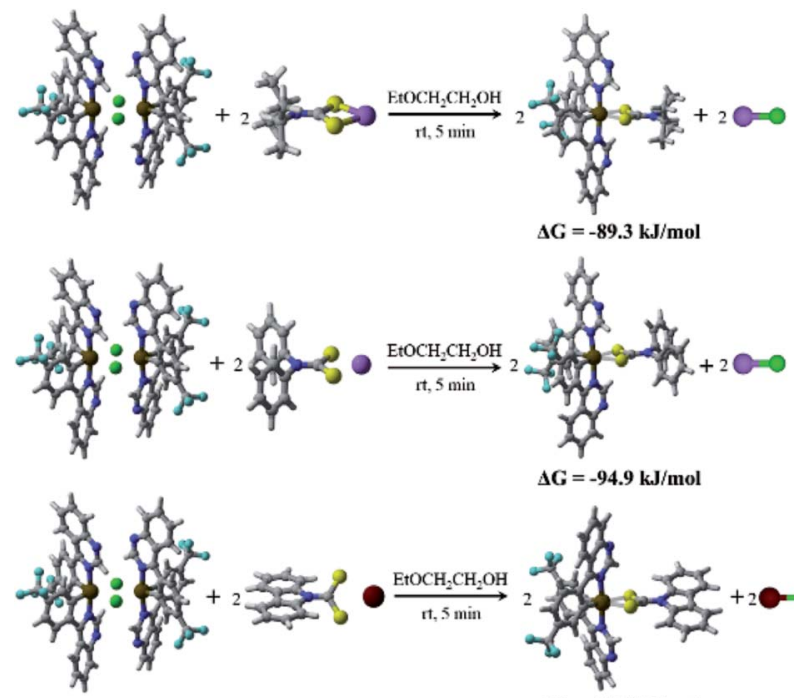

$\Delta G=-94.9 \mathrm{~kJ} / \mathrm{mol}$

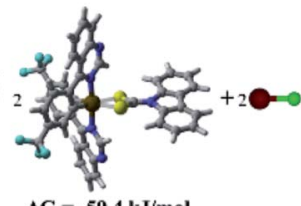

Fig. 1 The calculated Gibbs free energy change $\Delta G$ of the three reactions of $(4 \mathrm{tfmpq})_{2}\left|\mathrm{r}(\mathrm{dipdtc}),(4 \mathrm{tfmpq})_{2}\right| \mathrm{r}(\mathrm{dpdtc})$ and $(4 \mathrm{tfmpq})_{2}-$ $\operatorname{lr}($ Czdtc) complexes.

bond lengths/angles are summarized in Tables S1 and S2 $(\mathrm{ESI} \dagger)$, respectively. Both complexes have a distorted octahedral coordination geometry around the iridium center surrounded by three chelating ligands with cis-C-C and trans-N$\mathrm{N}$ dispositions in which the $\mathrm{N}-\mathrm{Ir}-\mathrm{N}$ angles for these complexes are all almost $175^{\circ}$. The four-membered $\mathrm{Ir}-\mathrm{S}-\mathrm{C}-\mathrm{S}$ backbones could lead to significantly more acute $\mathrm{S}-\mathrm{Ir}-\mathrm{S}$ bite angles $\left(71.4^{\circ}\right.$ and $\left.72.0^{\circ}\right)$ than seen for the larger five-

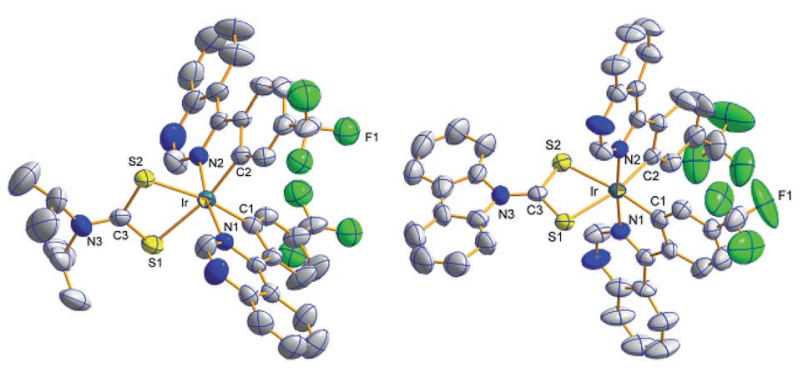

Fig. 2 ORTEP diagram of (4tfmpq) $)_{2}$ Ir(dipdtc) (CCDC no. 1832357) and $(4 \mathrm{tfmpq})_{2} \operatorname{Ir}(\mathrm{Czdtc})$ (CCDC no. 1832334) with the atom-numbering schemes. Hydrogen atoms are omitted for clarity. Ellipsoids are drawn at the $50 \%$ probability level. membered or six-membered heterocycles such as those based on pic and acac derivatives..$^{5,15,16}$ In (4tfmpq) ${ }_{2} \operatorname{Ir}(\mathrm{Czdtc})$, the bond length of $\mathrm{C} 3-\mathrm{S} 1(1.710 \AA)$ which is similar to that of C3-S2 (1.702 $\AA$ ) also illustrates that -1 charge of dithiocarbamate is scattered over both sulfur atoms. The two coordinated $\mathrm{S}$ atoms of the ancillary ligand reside in the equatorial plane trans to the metalated $\mathrm{C}(4 \mathrm{tfmpq})$ atoms. From the above analysis, this compact and tensile bonding mode is well understood.

\section{Electrochemical properties and theoretical calculations}

The highest occupied molecular orbital (HOMO) and lowest unoccupied molecular orbital (LUMO) energy levels of the dopants are important for the structure design of OLEDs. To determine the HOMO/LUMO energy levels, the electrochemical behaviors of the three complexes were measured by cyclic voltammetry in $\mathrm{CH}_{2} \mathrm{Cl}_{2}$ solution at room temperature, relative to an internal ferrocenium/ferrocene reference $\left(\mathrm{Fc}^{+} / \mathrm{Fc}\right.$ ) (Fig. $\mathrm{S} 4, \dagger$ and Table 1). As revealed previously by electrochemistry and theoretical calculations of cyclometalated Ir(III) complexes, it is generally considered that the reduction process occurs mainly on the heterocyclic portion of the cyclometalated $\mathrm{C}^{\wedge} \mathrm{N}$ ligands, whereas oxidation processes largely involve the Ir-aryl center and the ancillary ligand. ${ }^{17}$ Based on the above analysis, these complexes have almost equal LUMO energy levels $(-3.19$ to $-3.22 \mathrm{eV}$ ) due to the same quinazoline-based frame, whereas their HOMO levels systematically change with the variation of the ancillary ligands from $-5.44 \mathrm{eV}$ of $(4 \mathrm{tfmpq}){ }_{2} \operatorname{Ir}($ dipdtc) containing diisopropylamine to -5.50 and $-5.61 \mathrm{eV}$ of $(4 \mathrm{tfmpq})_{2} \operatorname{Ir}(\mathrm{dpdtc})$ and $(4 \mathrm{tfmpq})_{2} \operatorname{Ir}(\mathrm{Czdtc})$ complexes, respectively, by introducing the diphenylamine and carbazole groups into the ancillary ligands. These results suggest that the diphenylamine and carbazole groups in the ancillary ligands would stabilize the HOMO level and positively shift the oxidation potentials.

To obtain further electronic structure information, the HOMO/LUMO distributions of these Ir(III) molecules were also obtained with DFT calculations. As shown in Fig. S5, $\dagger$ the HOMO orbitals of the three Ir(III) complexes are mostly located on the $4 \mathrm{tfmpq}$ (43.55-47.90\%) together with the d orbitals of the iridium atom (39.42-47.66\%) with a small portion of the dithiocarbamate derivatives (8.66-12.67\%). And a larger scale distribution of electron clouds on the iridium atom also indicates an efficient MLCT of the phosphorescent complexes, crucial to high PL quantum efficiency. With the decrease of 
the electron-donating ability of the substituents from diisopropylamine and diphenylamine to carbazole, the electron clouds distributed over the dithiocarbamate derivatives decrease gradually from $12.67 \%$ and $8.79 \%$ to $8.66 \%$, which verifies the gradual change of the HOMO level of the corresponding complexes (Table S3†). The LUMOs are mostly distributed over the $\pi^{*}$ orbitals of the cyclometalated ligand (93.33-94.35\%) and to a small extent on Ir d orbitals (3.45$4.13 \%)$ and ancillary ligands (2.20-2.34\%). The calculated LUMOs remain almost unchanged, yet the HOMOs vary significantly, which correlate well with the electrochemical results (Table $\mathrm{S} 3 \dagger$ ).

\section{Photophysical properties}

Fig. 3 shows the ultraviolet-visible absorption and photoluminescence spectra of (4tfmpq) $)_{2} \operatorname{Ir}($ dipdtc $),(4 \mathrm{tfmpq})_{2} \operatorname{Ir}(\mathrm{dpdtc})$ and $(4 \mathrm{tfmpq})_{2} \operatorname{Ir}(\mathrm{Czdtc})$ complexes at room temperature in $\mathrm{CH}_{2} \mathrm{Cl}_{2}$, and their photophysical data are listed in Table 1 . The intense absorption bands below $400 \mathrm{~nm}$ arise from the spinallowed intraligand $\pi \rightarrow \pi^{*}$ transitions, and the relatively weak bands in the visible region (400-630 nm) can be assigned to the mixed ${ }^{1}$ MLCT and ${ }^{3}$ MLCT (metal-to-ligand chargetransfer) states, or the LLCT (ligand-to-ligand charge-transfer) transition through strong spin-orbit coupling of the iridium atom. ${ }^{18}$ Compared with the complex (4tfmpq) ${ }_{2} \operatorname{Ir}$ (dipdtc) using the $N, N$-diisopropyl dithiocarbamate ancillary ligand $\left(\lambda_{\text {peak }}=\right.$ $641 \mathrm{~nm}$, Fig. 3(b)), complexes $(4 \mathrm{tfmpq})_{2} \operatorname{Ir}(\mathrm{dpdtc})$ containing $\mathrm{N}, \mathrm{N}$-diphenyl dithiocarbamate and $(4 \mathrm{tfmpq})_{2} \operatorname{Ir}(\mathrm{Czdtc})$ with $\mathrm{N}$ carbazolyl dithiocarbamate exhibit 13 and $30 \mathrm{~nm}$ hypsochromic shifts, coinciding with the variation of calculated energy gaps.

The PL quantum yields of the three Ir(III) complexes were measured as $58.3 \%, 84.3 \%$ and $93.0 \%$, respectively, which may be attributed to the gradually increased rigidity of the corresponding Ir(III) complexes by gradually increasing the rigidity of the electron-donating substituents in the dithiocarbamate ancillary ligand from diisopropylamine and diphenylamine to carbazole. When the rigidity of the ligands is enhanced gradually, the non-radiative transitions caused by the vibration and rotation of a large number of $\mathrm{C}-\mathrm{H}$ and $\mathrm{C}-\mathrm{C}$ bonds are much reduced, which is also a way of energy consumption for the triplet states of the Ir(III) complexes. In addition, the lifetimes of the three complexes are in the microsecond range $(1.41 \mu$ s for $(4 \mathrm{tfmpq})_{2} \operatorname{Ir}\left(\right.$ dipdtc), $1.55 \mu \mathrm{s}$ for $(4 \mathrm{tfmpq})_{2} \operatorname{Ir}($ dpdtc $)$ and $1.50 \mu \mathrm{s}$
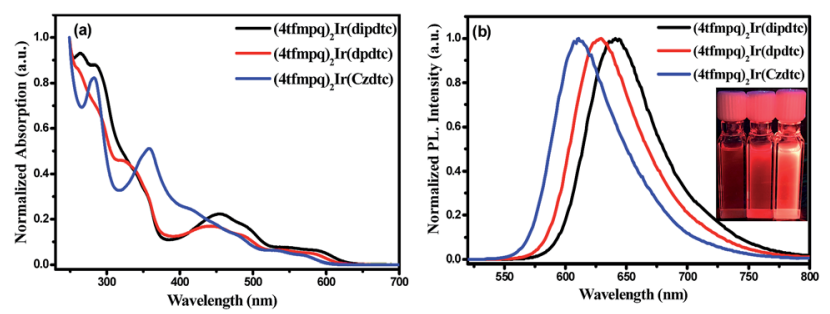

Fig. 3 The UV-vis absorption (a) and emission (b) spectra of the three complexes $(4 \mathrm{tfmpq})_{2} \mid \mathrm{r}$ (dipdtc), $(4 \mathrm{tfmpq})_{2} \mid r(\mathrm{dpdtc})$ and $(4 \mathrm{tfmpq})_{2}-$ $\operatorname{lr}(\mathrm{Czdtc})$ in degassed dichloromethane $\left(5 \times 10^{-5} \mathrm{M}\right)$ at room temperature. for $(4 \mathrm{tfmpq})_{2} \operatorname{Ir}(\mathrm{Czdtc})$, respectively) (Fig. S6 $\dagger$ ), which is indicative of the phosphorescence origin for the excited states in each case.

\section{OLED performance}

To illustrate their electroluminescence (EL) properties, typical OLEDs using these complexes as dopants were fabricated. Firstly, single-emissive-layer devices with ITO/HAT-CN (dipyrazino[2,3-f:2' , 3'-h]quinoxaline-2,3,6,7,10,11-hexacarbonitrile, 6 $\mathrm{nm}$ )/HAT-CN (0.2 wt\%):TAPC (di-[4-( $N, N$-ditolylamino) phenyl] cyclohexane, $50 \mathrm{~nm}) /(4 \mathrm{tfmpq})_{2} \operatorname{Ir}($ dipdtc $)$ or $(4 \mathrm{tfmpq})_{2} \operatorname{Ir}($ dpdtc $)$ or (4tfmpq) ${ }_{2} \operatorname{Ir}(\mathrm{Czdtc})$ (3 wt\%):2,6DCzPPy (2,6-bis(3-(carbazol-9yl)phenyl)pyridine, $10 \mathrm{~nm}$ )/Tm3PyP26PyB (1,3,5-tris(6-(3(pyridin-3-yl)phenyl)pyridin-2-yl) benzene, $60 \mathrm{~nm}$ )/LiF (1 nm)/Al $(100 \mathrm{~nm})$ are named as S1-S3, respectively. As shown in Scheme 2, the materials of HAT-CN and LiF served as hole- and electroninjecting interface modified materials, respectively. The bipolar material 2,6 DCzPPy was chosen as the host material. The TAPC material with a high HOMO level $(-5.5 \mathrm{eV})$ acts as the holetransport medium, and the layer of TAPC is doped with $0.2 \mathrm{wt} \%$ HAT-CN to further enhance the hole-transporting ability, while Tm3PyP26PyB with a low LUMO level $(-2.7 \mathrm{eV})$ is used as the electron-accepting and electron-transport material. The HOMO and LUMO levels of Ir(III) complexes were all embedded between those of 2,6 DCzPPy (HOMO $=6.10 \mathrm{eV}$ and LUMO $=2.60 \mathrm{eV}$ ). Thus, efficient energy transfer from the host to $\operatorname{Ir}(\mathrm{III})$ complexes occurred in the emitting layer (EML). Furthermore, holes and electrons can be injected to the HOMO and LUMO levels of the host material or trapped by the dopants directly owing to the difference of the HOMO/LUMO levels between the Ir(III) complexes and the host materials. And in the bipolar host 2,6 DCzPPy the excitons can be easily formed and distributed more balanced, which is helpful to reduce the turnon voltage. All the devices were optimized and they display the best EL performances all at $3 \mathrm{wt} \%$ doping concentration, and the details of optimizing the doping concentration of $\operatorname{Ir}(\mathrm{III})$ emitters are included in the ESI. $\uparrow$ The electroluminescence (EL) spectra, current density $(J)$-voltage $(V)$-luminance $(L)$, current efficiency $\left(\eta_{\mathrm{c}}\right)$ and power efficiency $\left(\eta_{\mathrm{p}}\right)$ versus luminance, and $\mathrm{EQE}$ as a function of luminance characteristics of the devices

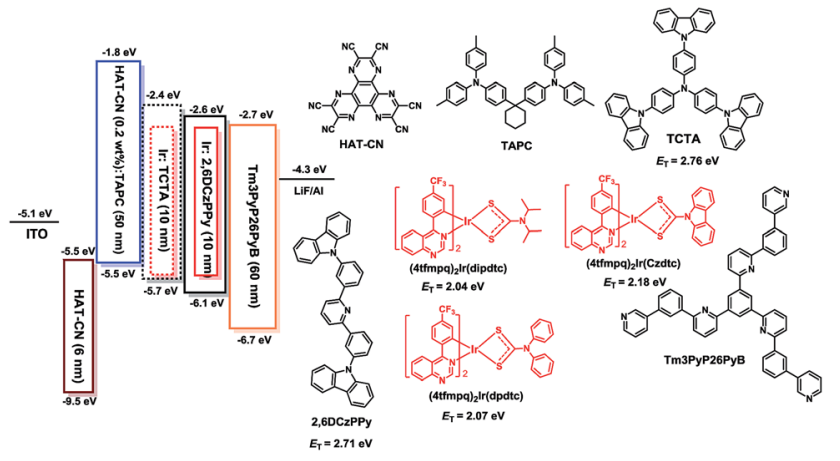

Scheme 2 Energy level diagram of the HOMO and LUMO levels of materials investigated and their chemical molecular structures. 

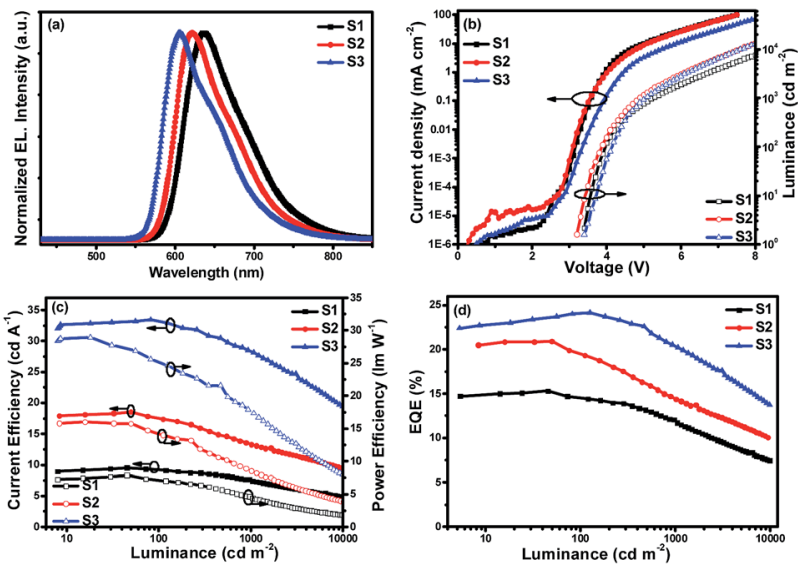

Fig. 4 Characteristics of single-emitting-layer devices: (a) EL spectra, (b) $J-V-L$ curves, (c) $\eta_{\mathrm{c}}-L-\eta_{\mathrm{p}}$ curves and (d) EQE $-L$ curves.

are displayed in Fig. 4, and the parameters of these devices are summarized in Table 2.

Fig. 4(a) shows the normalized EL spectra of the three devices measured at the current of $1 \mathrm{~mA}$ with peaks at about 636, 621 and $605 \mathrm{~nm}$ for devices S1-S3, which are very close to the PL spectra of the three Ir(III) complexes, indicating that the EL emission of the devices originates from the triplet excited states of the phosphors in which all the Commission Internationale de $1^{\prime}$ Eclairage (CIE) color coordinates fall in the red region. Due to the same cyclometalated ligand and similar molecular structures of the ancillary ligands, the device performances of these materials mainly depend on their PL efficiencies and bipolar properties. With the changes of the substituents from diisopropylamine and diphenylamine to carbazole, the resulting complexes from $(4 \mathrm{tfmpq})_{2} \operatorname{Ir}($ dipdtc) and $(4 \mathrm{tfmpq})_{2} \operatorname{Ir}(\mathrm{dpdtc})$ to $(4 \mathrm{tfmpq})_{2} \operatorname{Ir}(\mathrm{Czdtc})$ exhibit more notable bipolar properties, better carrier balances and enhanced photoluminescence quantum efficiency, which would lead to the gradually enhanced OLED performances.

Respectively, the device $\mathrm{S} 1\left(\Phi_{\mathrm{P}}\right.$ of $(4 \mathrm{tfmpq})_{2} \operatorname{Ir}($ dipdtc) is $58.3 \%$ ) shows the lowest EL performances with a maximum luminance $\left(L_{\max }\right)$ above $26000 \mathrm{~cd} \mathrm{~m}^{-2}$, a peak current efficiency $\left(\eta_{\mathrm{c}, \max }\right)$ of $9.81 \mathrm{~cd} \mathrm{~A}^{-1}$, a peak power efficiency $\left(\eta_{\mathrm{p}, \max }\right)$ of $7.86 \mathrm{~lm}$ $\mathrm{W}^{-1}$ and a maximum external quantum efficiency (EQE $\left.\mathrm{E}_{\max }\right)$ of $15.30 \%$. Relatively, the device $\mathrm{S} 2\left(\Phi_{\mathrm{P}}\right.$ of $(4 \mathrm{tfmpq})_{2} \operatorname{Ir}($ dpdtc $)$ is $84.3 \%$ ) displays better performances with a $L_{\max }, \eta_{\mathrm{c}, \max }$ and
$\mathrm{EQE}_{\max }$ of $39870 \mathrm{~cd} \mathrm{~m}^{-2}, 18.56 \mathrm{~cd} \mathrm{~A}^{-1}$ and $20.91 \%$, respectively. Due to the highest $\Phi_{\mathrm{P}}$ of $(4 \mathrm{tfmpq})_{2} \operatorname{Ir}(\mathrm{Czdtc})(93.0 \%)$, the device S3 exhibits the best characteristics with a $L_{\max }, \eta_{\mathrm{c}, \max }$ and $\mathrm{EQE}_{\max }$ of $56880 \mathrm{~cd} \mathrm{~m}^{-2}, 32.92 \mathrm{~cd} \mathrm{~A}^{-1}$ and $24.18 \%$, respectively.

In order to further improve the EL performances of these complexes, another hole transport material TCTA $\left(4,4^{\prime}, 4^{\prime \prime}\right.$ tris(carbazol-9-yl)triphenylamine) was introduced as the second host for these emitters and also as a "hole ladder" layer due to its suitable HOMO level $(-5.70 \mathrm{eV})$ between TAPC and 26DCzPPy (Scheme 2). The OLEDs with double emissive layers with the configuration of ITO/HAT-CN (6 nm)/HAT-CN (0.2 wt $\%):$ TAPC $(50 \mathrm{~nm}) / \operatorname{Ir}(\mathrm{III})$ complexes $(x \mathrm{wt} \%)$ :TCTA $(10$ $\mathrm{nm}) / \mathrm{Ir}(\mathrm{III})$ complexes $(x$ wt $\%): 2,6 \mathrm{DCzPPy}(10 \mathrm{~nm}) / \mathrm{Tm} 3 \mathrm{PyP} 26 \mathrm{PyB}$ $(60 \mathrm{~nm}) / \mathrm{LiF}(1 \mathrm{~nm}) / \mathrm{Al}(100 \mathrm{~nm})$ using the dopants of $(4 \mathrm{tfmpq})_{2} \operatorname{Ir}(\text { dipdtc), (4tfmpq) })_{2} \operatorname{Ir}(\text { dpdtc) and (4tfmpq) })_{2} \operatorname{Ir}$ (Czdtc) are named as D1-D3, respectively (Scheme 2). The corresponding EL characteristics of the devices are shown in Fig. 5, and the detailed results are also summarized in Table 2 . The stepwise changed HOMO energy levels of TAPC $(-5.5 \mathrm{eV})$, TCTA $(-5.7 \mathrm{eV})$ and 2,6DCzPPy $(-6.1 \mathrm{eV})$ are beneficial for the hole injection and transport. Similarly, they are also beneficial for the injection and transport of electrons owing to the gradually changed LUMO energy levels of Tm3PyP26PyB (-2.7 eV), 2,6DCzPPy $(-2.6 \mathrm{eV})$ and TCTA $(-2.4 \mathrm{eV})$. Thus, holes and electrons will be distributed in more balanced emissive layers and the exciton recombination zone is expected to be broadened. Furthermore,
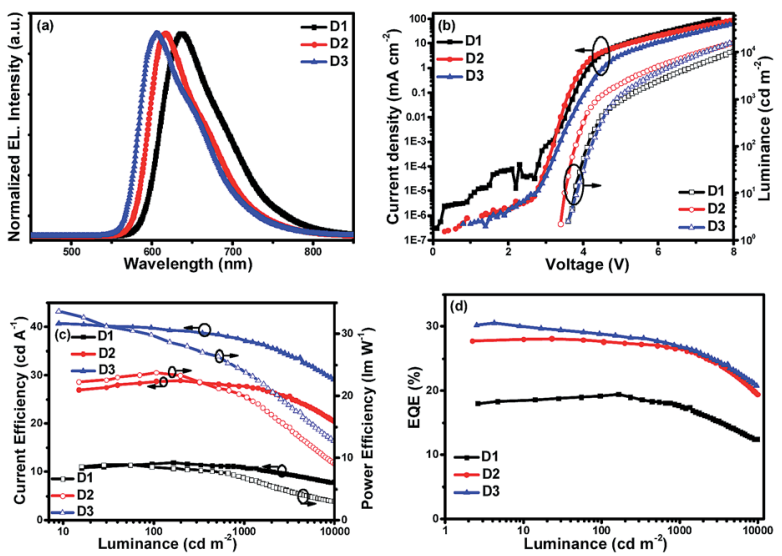

Fig. 5 Characteristics of double emitting-layer devices: (a) EL spectra, (b) $J-V-L$, (c) $\eta_{\mathrm{c}}-L-\eta_{\mathrm{p}}$ and (d) EQE- $L$ curves.

Table 2 The key EL data of devices S1-S3 and D1-D3

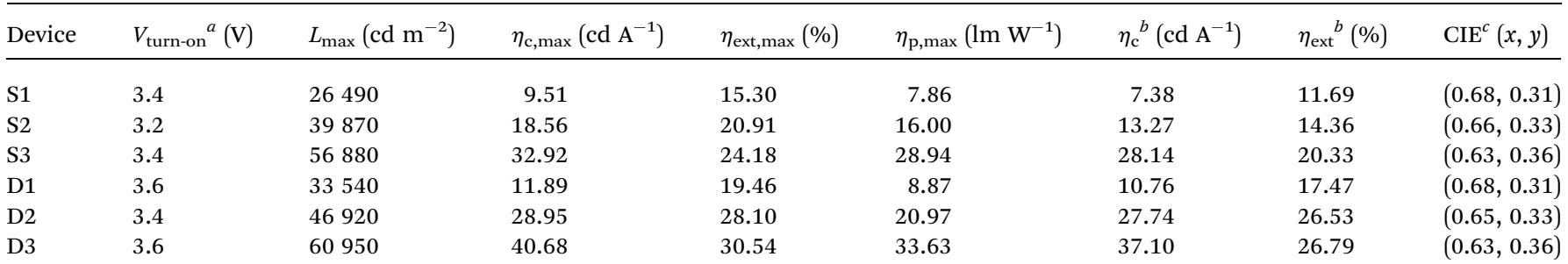

${ }^{a}$ Applied voltage recorded at a luminance of $1 \mathrm{~cd} \mathrm{~m}^{-2} .{ }^{b}$ Recorded at $1000 \mathrm{~cd} \mathrm{~m}^{-2} .^{c}$ Measured at $1000 \mathrm{~cd} \mathrm{~m}^{-2}$. 
the Tm3PyP26PyB HOMO energy level is $0.6 \mathrm{eV}$ lower than that of 2,6DCzPPy and the TAPC LUMO energy level is $0.6 \mathrm{eV}$ higher than that of TCTA, which will result in excitons (hole-electron pairs) being well conformed within emissive layers and the triplet exciton quenching being avoided effectively. From Fig. 5 and Table 2, it can be observed that all the devices with double emissive layers show better performances than S1-S3.

Respectively, D1 based on (4tfmpq) $)_{2} \operatorname{Ir}($ dipdtc) at a doping concentration of $3 \mathrm{wt} \%$ displayed good performances with a $L_{\text {max }}$ above $33000 \mathrm{~cd} \mathrm{~m}^{-2}, \eta_{\mathrm{c}, \max }$ over $11.89 \mathrm{~cd} \mathrm{~A}^{-1}, \eta_{\mathrm{p}, \max }$ over $8.87 \mathrm{~lm} \mathrm{~W}^{-1}$ and $\mathrm{EQE}_{\max }$ of $19.46 \%$. The device $\mathrm{D} 2$ based on $(4 \mathrm{tfmpq})_{2} \operatorname{Ir}(\mathrm{dpdtc})$ at a doping concentration of $1 \mathrm{wt} \%$ displayed higher characteristics with a $L_{\max }$ of $46920 \mathrm{~cd} \mathrm{~m}^{-2}$, an $\eta_{\mathrm{c}, \max }$ of $28.95 \mathrm{~cd} \mathrm{~A}^{-1}$, an $\eta_{\mathrm{p}, \max }$ of $20.97 \mathrm{~lm} \mathrm{~W}^{-1}$ and an $\mathrm{EQE}_{\max }$ of $28.10 \%$ with CIE coordinates of $(0.65,0.33)$, which are quite close to the standard red demanded by the National Television System Committee (NTSC). Device D3 based on (4tfmpq) ${ }_{2}^{-}$ $\operatorname{Ir}(\mathrm{Czdtc})$ with the $\mathrm{N}$-carbazolyl dithiocarbamate ancillary ligand at $3 \mathrm{wt} \%$ doped concentration showed the best EL performances with a high brightness of $60950 \mathrm{~cd} \mathrm{~m}^{-2}$ and the $\eta_{\mathrm{c}, \max }, \mathrm{EQE}_{\max }$ and $\eta_{\mathrm{p}, \max }$ are up to $40.68 \mathrm{~cd} \mathrm{~A}^{-1}, 30.54 \%$ and $33.63 \mathrm{~lm} \mathrm{~W}^{-1}$, respectively. The CIE coordinates of $(0.63,0.36)$ also fall in the red region. The EQEs of $30.54 \%$ and the maximum brightness of $60950 \mathrm{~cd} \mathrm{~m}^{-2}$ are among the highest results ever reported for red Ir(III) complexes. ${ }^{7}$ Furthermore, the device efficiency roll-off is not serious. As for device D3, the $\eta_{\mathrm{c}}$ and EQE can still be obtained as $37.10 \mathrm{~cd} \mathrm{~A}^{-1}$ and $26.79 \%$, respectively, when the luminance reaches $1000 \mathrm{~cd} \mathrm{~m}^{-2}$.

Summarized from the investigated results, the superior device properties may result from the following facts. Firstly, dithiocarbamate derivatives with different electron-donating moieties and the nitrogen frame of 4-(4-(trifluoromethyl) phenyl)quinazoline were applied as the ancillary ligands and cyclometalated ligand for stable Ir(III) complexes with bipolar properties, which may contribute to a wider recombination area and a more balanced distribution for the excitons. Secondly, the coordination capability of the sulfur atom with the iridium atom is strong, and the stable dithiolate compounds can reduce the work function of the emitter and the threshold electric field. ${ }^{8}$ The different dithiocarbamate derivatives can lower the LUMO energy levels of the complexes, and the electron transport properties can benefit from lowering the LUMO levels of the dopants. Finally, double light-emitting layers were adopted, which showed improved and balanced charge-injection/ transporting properties compared to single layer-emitting devices. ${ }^{19}$

\section{Conclusions}

In conclusion, three cyclometalated $\operatorname{Ir}(\mathrm{III})$ complexes containing the unique four-membered Ir-S-C-S backbone ring were rapidly prepared at room temperature with good yields above $70 \%$ and high PLQYs up to $93.0 \%$ in $\mathrm{CH}_{2} \mathrm{Cl}_{2}$. The Gibbs free energy calculation results confirm that all reactions are exothermic and thermodynamically favorable processes. Through changing the ancillary ligands with different electrondonating groups, the rigidity and bipolar properties of these
Ir(III) complexes can be effectively tuned, resulting in regularly changed emission wavelength and OLED performances. The double-emissive-layer devices using the complex with $N$-carbazolyl dithiocarbamate as the ancillary ligand displays exceedingly good performances with a maximum brightness over $60000 \mathrm{~cd} \mathrm{~m}^{-2}$ and an $\mathrm{EQE}_{\max }$ of $30.54 \%$. Even at the brightness of $1000 \mathrm{~cd} \mathrm{~m}^{-2}$, the EQE can still be obtained as $26.79 \%$, respectively. This study provides a useful route to synthesize Ir(III) complexes with the four-membered ring Ir-S-C-S structure rapidly, which is key to the industrial production of phosphorescent materials for high-performance OLEDs.

\section{Experimental section}

\section{Synthesis of the salts of dithiocarbamate derivatives}

Lithium $\boldsymbol{N}, \boldsymbol{N}$-diisopropyl dithiocarbamate (Li-dipdtc). Diisopropyl amine ( $40 \mathrm{mmol}$ ) was added to a stirring slurry of $\mathrm{LiOH}$ $(2.0 \mathrm{~g}, 48 \mathrm{mmol})$ in water $(3 \mathrm{~mL})$ and $\mathrm{CS}_{2}(3.6 \mathrm{~g}, 48 \mathrm{mmol})$ in benzene $(10 \mathrm{~mL})$. An exothermic reaction ensued, followed by formation of yellow to orange precipitates. After $1 \mathrm{~h}$, petroleum ether was added and the reaction mixture was filtered. The solids were washed well with petroleum ether and dried in vacuo to give a white to pale yellow solid, which was used in the next procedure without further purification.

Lithium $\boldsymbol{N}, \boldsymbol{N}$-diphenyl dithiocarbamate (Li-dpdtc). A solution of diphenylamine $(500 \mathrm{mg}, 2.96 \mathrm{mmol})$ was dissolved in degassed THF $(6 \mathrm{~mL})$, then cooled to $0{ }^{\circ} \mathrm{C}$ and treated with $n$-BuLi (30 mL, $5.92 \mathrm{mmol})$. After stirring for $30 \mathrm{~min}$ at $0{ }^{\circ} \mathrm{C}, \mathrm{CS}_{2}$ ( $2 \mathrm{~mL}, 29.6 \mathrm{mmol}$ ) was added. The ice bath was removed and stirred for $12 \mathrm{~h}$ at room temperature. The crude mixture was recrystallized from THF in $\mathrm{Et}_{2} \mathrm{O}$, to afford lithium $N, N$-diphenyl dithiocarbamate as an off-white solid, which was used in the next procedure without further purification.

Sodium $\mathbf{N}$-carbazolyl dithiocarbamate (Na-Czdtc). Carbazole powder ( $3.34 \mathrm{~g}, 0.02 \mathrm{~mol}$ ) dissolved in $30 \mathrm{~mL}$ of THF was added dropwise into $0.72 \mathrm{~g}$ of $\mathrm{NaH}(0.03 \mathrm{~mol})$ suspended in $5 \mathrm{~mL}$ of THF in an ice-water bath under a $\mathrm{N}_{2}$ atmosphere. Afterwards, the mixture was stirred for another $15 \mathrm{~min}$ at room temperature. Then, $1.33 \mathrm{~mL}$ of $\mathrm{CS}_{2}(0.022 \mathrm{~mol})$ was added dropwise into the system. The system was subsequently immersed in an oil bath at $40{ }^{\circ} \mathrm{C}$ and reacted for $3 \mathrm{~h}$. During the reaction time, the color of the system gradually turned dull-red. The system of sodium thionocarboxylate in THF was quenched by adding a small amount of water in an ice-water bath. After the solvent was removed from the reaction mixture, $100 \mathrm{~mL}$ of water was added into the residue, and the aqueous phase was filtered. The filtrate was washed with diethyl ether three times to obtain pure sodium thionocarboxylate aqueous solution, which was used in the next procedure without further purification.

\section{Synthesis of iridium(III) complexes}

$\operatorname{IrCl}_{3}(0.64 \mathrm{~g}, 2.14 \mathrm{mmol})$ and 2.4 equivalents of cyclometalated ligand $(5.14 \mathrm{mmol})$ were added in a 2-ethoxyethanol and water mixture. Then, the solution was heated for $16 \mathrm{~h}$ at $110{ }^{\circ} \mathrm{C}$. After the addition of water, the precipitated red powder of $\left[\left(\mathrm{C}^{\wedge} \mathrm{N}\right)_{2} \operatorname{Ir}(\mu-\mathrm{Cl})\right]_{2}$ chloride-bridged dimer was filtered and 
reacted with dithiocarbamate derivatives without further purification for 5 minutes at room temperature in $\mathrm{EtOCH}_{2} \mathrm{CH}_{2} \mathrm{OH}$. Then the solution was concentrated and the resulting residue was purified by silica gel column chromatography $\left(\mathrm{CH}_{2} \mathrm{Cl}_{2} /\right.$ petroleum ether $1: 2(\mathrm{v} / \mathrm{v}))$ and vacuum sublimation gave red crystals.

(4tfmpq) $)_{2} \operatorname{Ir}$ (dipdtc). Yield: $77 \% .{ }^{1} \mathrm{H}$ NMR $\left(400 \mathrm{MHz}, \mathrm{CDCl}_{3}\right.$ ) $\delta 10.43(\mathrm{~s}, 2 \mathrm{H}), 8.85(\mathrm{~d}, J=8.6 \mathrm{~Hz}, 2 \mathrm{H}), 8.43(\mathrm{~d}, J=8.4 \mathrm{~Hz}, 2 \mathrm{H})$, $8.29(\mathrm{~d}, J=8.0 \mathrm{~Hz}, 2 \mathrm{H}), 8.04-7.96(\mathrm{~m}, 2 \mathrm{H}), 7.88-7.83(\mathrm{~m}, 2 \mathrm{H})$, $7.18(\mathrm{dd}, J=8.4,1.3 \mathrm{~Hz}, 2 \mathrm{H}), 6.74(\mathrm{~s}, 2 \mathrm{H}), 1.37(\mathrm{~d}, J=6.8 \mathrm{~Hz}$, $8 \mathrm{H}), 1.28-1.22(\mathrm{~m}, 4 \mathrm{H}) .{ }^{19} \mathrm{~F}$ NMR $\left(377 \mathrm{MHz}, \mathrm{CDCl}_{3}\right) \delta-63.19(\mathrm{~s})$. HR-MS, $m / z$ : calcd for $\mathrm{C}_{37} \mathrm{H}_{30} \mathrm{~N}_{5} \mathrm{~F}_{6} \mathrm{~S}_{2} \mathrm{Ir}, 915.1476$ [M]; found 916.1557 [M + H] $]^{+}$. Anal. calcd for $\mathrm{C}_{37} \mathrm{H}_{30} \mathrm{~N}_{5} \mathrm{~F}_{6} \mathrm{~S}_{2} \mathrm{Ir}: \mathrm{C}$, 48.57; H, 3.30 ; N, 7.65. Found: C, 48.67; H, 3.32; N, 7.75\%.

(4tfmpq) $)_{2} \mathbf{I r}(\mathrm{dpdtc})$. Yield: $75 \% .{ }^{1} \mathrm{H}$ NMR $\left(400 \mathrm{MHz}, \mathrm{CDCl}_{3}\right)$ $\delta 10.31(\mathrm{~d}, J=2.4 \mathrm{~Hz}, 2 \mathrm{H}), 8.73(\mathrm{~d}, J=8.5 \mathrm{~Hz}, 2 \mathrm{H}), 8.30(\mathrm{~d}, J=$ $8.4 \mathrm{~Hz}, 2 \mathrm{H}), 8.24(\mathrm{~d}, J=8.2 \mathrm{~Hz}, 2 \mathrm{H}), 7.93(\mathrm{t}, J=7.7 \mathrm{~Hz}, 2 \mathrm{H}), 7.76$ $(\mathrm{dd}, J=8.4,7.2 \mathrm{~Hz}, 2 \mathrm{H}), 7.42-7.32(\mathrm{~m}, 6 \mathrm{H}), 7.32-7.24(\mathrm{~m}, 2 \mathrm{H})$, 7.23-7.17 (m, 2H), $7.07(\mathrm{dd}, J=8.4,1.2 \mathrm{~Hz}, 2 \mathrm{H}), 6.66(\mathrm{~s}, 2 \mathrm{H}) .{ }^{19} \mathrm{~F}$ NMR $\left(377 \mathrm{MHz}, \mathrm{CDCl}_{3}\right) \delta-63.25$ (s). HR-MS, $m / z$ : calcd for $\mathrm{C}_{43} \mathrm{H}_{26} \mathrm{~N}_{5} \mathrm{~F}_{6} \mathrm{~S}_{2} \mathrm{Ir}, 983.1163[\mathrm{M}]$; found $984.1247[\mathrm{M}+\mathrm{H}]^{+}$. Anal. calcd for $\mathrm{C}_{43} \mathrm{H}_{26} \mathrm{~N}_{5} \mathrm{~F}_{6} \mathrm{~S}_{2} \mathrm{Ir}$ : C, 52.54; H, 2.67; N, 7.12. Found: C, 52.74; H, 2.47; N, 7.32\%.

(4tfmpq) $)_{2} \mathbf{I r}$ (Czdtc). Yield: $70 \% .{ }^{1} \mathrm{H}$ NMR $\left(400 \mathrm{MHz}, \mathrm{CDCl}_{3}\right)$ $\delta 10.33(\mathrm{~s}, 2 \mathrm{H}), 9.35-9.18(\mathrm{~m}, 2 \mathrm{H}), 8.84(\mathrm{~d}, J=8.5 \mathrm{~Hz}, 2 \mathrm{H}), 8.47$ $(\mathrm{d}, J=8.4 \mathrm{~Hz}, 2 \mathrm{H}), 8.24(\mathrm{~d}, J=8.2 \mathrm{~Hz}, 2 \mathrm{H}), 8.03-7.95(\mathrm{~m}, 2 \mathrm{H})$, 7.95-7.89 (m, 2H), 7.85 (dd, $J=11.5,4.1 \mathrm{~Hz}, 2 \mathrm{H}), 7.40-7.30(\mathrm{~m}$, 4H), 7.30-7.22 (m, 2H), $\left.6.82(\mathrm{~s}, 2 \mathrm{H}) .{ }^{19} \mathrm{~F} \mathrm{NMR} \mathrm{(377} \mathrm{MHz,} \mathrm{CDCl}_{3}\right)$ $\delta-63.18$ (s). HR-MS, $m / z$ : calcd for $\mathrm{C}_{43} \mathrm{H}_{24} \mathrm{~N}_{5} \mathrm{~F}_{6} \mathrm{~S}$ Ir, 981.1007 $[\mathrm{M}]$; found $982.1090[\mathrm{M}+\mathrm{H}]^{+}$. Anal. calcd for $\mathrm{C}_{43} \mathrm{H}_{24} \mathrm{~N}_{5} \mathrm{~F}_{6} \mathrm{~S}_{2} \mathrm{Ir}$ : C, $52.65 ; \mathrm{H}, 2.47$; N, 7.14. Found: C, 52.47; H, 2.61; N, 6.99\%.

\section{Conflicts of interest}

There are no conflicts to declare.

\section{Acknowledgements}

This work was supported by the National Natural Science Foundation of China (51773088 and 21771172) and Youth Innovation Promotion Association of Chinese Academy of Sciences (Y72014).

\section{Notes and references}

1 (a) J. P. Duan, P. P. Sun and C. H. Cheng, Adv. Mater., 2003, 15, 224; (b) G. J. Zhou, C. L. Ho, W. Y. Wong, Q. Wang, D. G. Ma, L. X. Wang, Z. Y. Lin, T. B. Marder and A. Beeby, Adv. Funct. Mater., 2008, 18, 499; (c) S. Lamansky, P. Djurovich, D. Murphy, F. Abdel-Razzaq, H. E. Lee, C. Adachi, P. E. Burrows, S. R. Forrest and M. E. Thompson, J. Am. Chem. Soc., 2001, 123, 4304.

2 (a) T.-H. Han, Y. Lee, M.-R. Choi, S.-H. Woo, S.-H. Bae, B. H. Hong, J.-H. Ahn and T. W. Lee, Nat. Photonics, 2012, 6, 105; (b) C. W. Lee and J. Y. Lee, Adv. Mater., 2013, 25, 5450; (c) S.-Y. Kim, W.-I. Jeong, C. Mayr, Y.-S. Park, K.-H. Kim, J.-H. Lee, C.-K. Moon, W. Brütting and J.-J. Kim,
Adv. Funct. Mater., 2013, 23, 3896; (d) P. Tao, Y. Miao, Y. Zhang, K. Wang, H. Li, L. Li, X. Li, T. Yang, Q. Zhao, H. Wang, S. Liu, X. Zhou, B. Xu and W. Huang, Org. Electron., 2017, 45, 293.

3 (a) Q. Wang, I. W. H. Oswald, X. Yang, G. Zhou, H. Jia, Q. Qiao, Y. Chen, J. Hoshikawa-Halbert and B. E. Gnade, Adv. Mater., 2014, 26, 8107; (b) K. Udagawa, H. Sasabe, C. Cai and J. Kido, Adv. Mater., 2014, 26, 5062; (c) J.-H. Lee, S.-H. Cheng, S.-J. Yoo, H. Shin, J.-H. Chang, C.-I. Wu, K.-T. Wong and J.-J. Kim, Adv. Funct. Mater., 2015, 25, 361; (d) P. Tao, Y. Zhang, J. Wang, L. Wei, H. Li, X. Li, Q. Zhao, X. Zhang, S. Liu, H. Wang and W. Huang, J. Mater. Chem. C, 2017, 5, 9306.

4 (a) C.-Y. Lu, M. Jiao, W.-K. Lee, C.-Y. Chen, W.-L. Tsai, C.-Y. Lin and C.-C. Wu, Adv. Funct. Mater., 2016, 26, 3250; (b) H. Shin, J.-H. Lee, C.-K. Moon, J.-S. Huh, B. Sim and J.-J. Kim, Adv. Mater., 2016, 28, 4920; (c) P. Tao, W. Li, J. Zhang, S. Guo, Q. Zhao, H. Wang, B. Wei, S. Liu, X. Zhou, Q. Yu, B. Xu and W. Huang, Adv. Funct. Mater., 2016, 26, 881.

5 (a) Q. Zhang, X. Wang, X. Wang, L. Wang and J. Zhang, Org. Electron., 2016, 33, 281; (b) P. Padungros and A. Wei, Synth. Commun., 2014, 44, 2336; (c) S. C. Ngo, K. K. Banger, M. J. DelaRosa, P. J. Toscano and J. T. Welch, Polyhedron, 2003, 22, 1575; (d) N. Su, Z. G. Wu and Y. X. Zheng, Dalton Trans., 2018, 47, 7587; (e) H. B. Han, Z. G. Wu, Z. P. Yan, Y. Zhao and Y. X. Zheng, Dalton Trans., 2018, 47, 16543.

6 (a) D. Q. Gao, F. Scholz, H. G. Nothofer, W. E. Ford, U. Scherf, J. M. Wessels, A. Yasuda and F. V. Wrochem, J. Am. Chem. Soc., 2011, 133, 5921; (b) L. Q. Chen, C. L. Yang, J. G. Qin, J. Gao, H. You and D. G. Ma, J. Organomet. Chem., 2006, 691, 3519; (c) K. A. King, P. J. Spellane and R. J. Watts, J. Am. Chem. Soc., 1985, 107, 1431; (d) A. Juris, V. Balzani, F. Barigelletti, S. Campagna, P. Belser and A. von Zelewsky, Coord. Chem. Rev., 1988, 84, 85.

7 (a) J. S. Wilson, N. Chawdhury, M. R. A. Al-Mandhary, M. Younus, M. S. Khan, P. R. Raithby, A. Köhler and R. H. Friend, J. Am. Chem. Soc., 2001, 123, 9412; (b) G. Zhou, W.-Y. Wong, B. Yao, Z. Xie and L. Wang, Angew. Chem., Int. Ed., 2007, 119, 1167; (c) X. Cao, J. Miao, M. Zhu, C. Zhong, C. Yang, H. Wu, J. Qin and Y. Cao, Chem. Mater., 2015, 27, 96; (d) M. Zhu, T. Ye, X. He, X. Cao, C. Zhong, D. Ma, J. Qin and C. Yang, J. Mater. Chem., 2011, 21, 9326; (e) J. Ding, J. Lü, Y. Cheng, Z. Xie, L. Wang, X. Jing and F. Wang, Adv. Funct. Mater., 2008, 18, 2754; (f) D. H. Kim, N. S. Cho, H. Y. Oh, J. H. Yang, W. S. Jeon, J. S. Park, M. C. Suh and J. H. Kwon, Adv. Mater., 2011, 23, 2721; $(g)$ B. Jiang, X. W. Ning, S. L. Gong, N. Jiang, C. Zhong, Z. H. Lu and C. L. Yang, J. Mater. Chem., 2017, 5, 10220; (h) L. Chen, S. Wang, Z. Yan, J. Ding and L. Wang, J. Mater. Chem. C, 2017, 5, 5749; (i) C. Y. Kuei, W. L. Tsai, B. H. Tong, M. Jiao, W. K. Lee, Y. Chi, C. C. Wu, S. H. Liu, G. H. Lee and P. T. Chou, Adv. Mater., 2016, 28, 2795; (j) Y. Q. Miao, P. Tao, K. X. Wang, H. X. Li, B. Zhao, L. Gao, H. Wang, B. S. Xu and Q. Zhao, ACS Appl. Mater. Interfaces, 2017, 9, 37873.

8 (a) T. Peng, H. Bi, Y. Liu, Y. Fan, H. Z. Gao, Y. Wang and Z. M. Hou, J. Mater. Chem., 2009, 19, 8072; (b) Q. B. Mei, 
C. Chen, R. Q. Tian, M. Yang, B. H. Tong, Q. F. Hua, Y. J. Shi, Q. L. Fan and S. H. Ye, RSC Adv., 2016, 6, 64003.

9 (a) H. B. Han, R. Z. Cui, Y. M. Jing, G. Z. Lu, Y. X. Zheng, L. Zhou, J. L. Zuo and H. J. Zhang, J. Mater. Chem. C, 2017, 5, 8150; (b) H. B. Han, R. Z. Cui, G. Z. Lu, Z. G. Wu, Y. X. Zheng, L. Zhou and H. J. Zhang, Dalton Trans., 2017, 46, 14916.

10 (a) C. Jones, P. C. Junk, J. A. Platts and A. Stasch, J. Am. Chem. Soc., 2006, 128, 2206; (b) L. Zhang, M. Nishiura, M. Yuki, Y. Luo and Z. Hou, Angew. Chem., Int. Ed., 2008, 47, 2642; (c) G. M. Li, P. Li, X. M. Zhuang, K. Q. Ye, Y. Liu and Y. Wang, ACS Appl. Mater. Interfaces, 2017, 9, 11749.

11 (a) J. A. R. Schmidt and J. Arnold, Chem. Commun., 1999, 2149; (b) D. Abeysekera, K. N. Robertson, T. S. Cameron and J. A. C. Clyburne, Organometallics, 2001, 20, 5532; (c) S. Bambirra, D. van Leusen, A. Meetsma, B. Hessen and J. H. Teuben, Chem. Commun., 2003, 522.
12 A. D. Becke, J. Chem. Phys., 1993, 98, 5648.

13 P. J. Hay and W. R. J. Wadt, Chem. Phys., 1985, 82, 270.

14 A. V. Marenich, C. J. Cramer and D. G. Truhlar, J. Phys. Chem. $B, 2009,113,6378$.

15 P. J. Hay, J. Phys. Chem. A, 2002, 106, 1634.

16 (a) Q. B. Mei, L. X. Wang, Y. H. Gao, J. N. Weng, F. Yan, B. Tian and B. H. Tong, J. Mater. Chem., 2012, 22, 6878; (b) X. L. Yang, X. B. Xu, J. S. Dang, G. J. Zhou, C. L. Ho and W. Y. Wong, Inorg. Chem., 2016, 55, 1720.

17 J. Brooks, Y. Babayan, S. Lamansky, P. I. Djurovich, I. Tsyba, R. Bau and M. E. Thompson, Inorg. Chem., 2002, 41, 3055.

18 Y. T. Tao, C. L. Yang and J. G. Qin, Chem. Soc. Rev., 2011, 40, 2943.

19 (a) Y. Jiang, L. Zhou, R. Cui, Y. Li, X. Zhao and H. Zhang, Dyes Pigm., 2016, 128, 26; (b) X. Zhao, L. Zhou, Y. Jiang, R. Cui, Y. Li and H. Zhang, Dyes Pigm., 2016, 130, 148. 